\title{
Incidence of non-physiologically complex surgical procedures performed in children: an Ontario population-based study of health administrative data
}

\section{Incidence des interventions chirurgicales non complexes d'un point de vue physiologique réalisées chez des enfants : une étude ontarienne des données administratives de santé fondée sur la population}

\author{
James D. O'Leary, MM, MD • Franklin Dexter, MD, PhD • David Faraoni, MD, PhD • \\ Mark W. Crawford, MBBS \\ Received: 18 May 2017/Revised: 25 August 2017/Accepted: 28 August 2017/Published online: 17 November 2017 \\ (C) Canadian Anesthesiologists' Society 2017
}

\begin{abstract}
Purpose Quantification of surgical procedures undertaken by hospitals is necessary for informing resource allocation and modelling healthcare services. Our objective was to quantify the incidence, similarity, and diversity of nonphysiologically complex surgical procedures performed at pediatric specialist hospitals and other hospitals performing pediatric surgery.

Methods We conducted a population-based cohort study of children aged 28 days to 18 yr who underwent surgery in the province of Ontario from 2007 to 2015 using healthcare administrative databases. We estimated the incidence of non-physiologically complex procedures (i.e., $\leq 7$ basic units in the 2015 Ontario Health Insurance Plan
\end{abstract}

Electronic supplementary material The online version of this article (doi:10.1007/s12630-017-0993-y) contains supplementary material, which is available to authorized users.

J. D. O'Leary, MM, MD · D. Faraoni, MD, PhD .

M. W. Crawford, MBBS

Department of Anesthesia, University of Toronto, Toronto, ON, Canada

J. D. O'Leary, MM, MD ( $₫) \cdot$ D. Faraoni, MD, PhD .

M. W. Crawford, MBBS

Department of Anesthesia and Pain Medicine, The Hospital for

Sick Children, Toronto, ON, Canada

e-mail: james.oleary@sickkids.ca

F. Dexter, MD, PhD

Division of Management Consulting, Department of Anesthesia,

University of Iowa, Iowa City, IA, USA
Schedule of Benefits) performed in pediatric specialist hospitals and other hospitals performing pediatric surgery. We used Yue and Clayton's index and the effective number of common procedures (1/Herfindahl index) to quantify the similarity and diversity of pediatric surgical procedures performed in these hospital types.

Results Overall, 830,830 pediatric surgical procedures were performed in 158 Ontario hospitals during the eightyear study period. Most surgical procedures performed at hospitals performing pediatric surgery were nonphysiologically complex (vs 50\%, $P<0.001$ ). The incidence of non-physiologically complex procedures increased progressively each year at pediatric specialist hospitals and was associated with a reciprocal decline among the other hospitals. Comparing pediatric specialist hospitals with the other hospitals, the mean similarity index for non-physiologically complex procedures was less than moderate $(0.52 ; 95 \%$ confidence interval [CI], 0.51 to 0.54). The mean effective number of common nonphysiologically complex procedures (i.e., the diversity) among the pediatric specialist hospitals was greater than at the other 154 hospitals performing pediatric surgery (65.3 vs 21.8 procedures, respectively; mean difference, 43.5; 95\% CI, 42.2 to 44.8; $P<0.001$ ).

Conclusions Non-physiologically complex procedures have progressively migrated to pediatric specialist hospitals from other hospitals in Ontario. Specialty pediatric hospitals are principally dissimilar from other hospitals performing pediatric surgery based not on physiological complexity, but on their diversity. These findings suggest that some types of surgical procedures 
may be redistributed from specialist pediatric hospitals to other hospitals performing pediatric surgery.

Trial registration $w w w . c l i n i c a l t r i a l s . g o v, \quad n u m b e r$ NCT03144544. Registered 2 May 2016.

\section{Résumé}

Objectif La quantification des interventions chirurgicales entreprises par les hôpitaux est nécessaire si l'on souhaite optimiser l'affectation des ressources et réaliser des modèles des services de soins de santé. Notre objectif était de quantifier l'incidence, les similitudes et la diversité des interventions chirurgicales non complexes, d'un point de vue physiologique, entre les hôpitaux spécialisés en pédiatrie et les autres hôpitaux réalisant des chirurgies pédiatriques.

Méthode Nous avons réalisé une étude de cohorte basée sur une population d'enfants âgés de 28 jours à 18 ans et beneficiant d'un intervention chirurgicale en Ontario entre 2007 et 2015 en nous fondant sur les bases de données administratives des soins de santé. Nous avons estimé l'incidence des interventions non complexes d'un point de vue physiologique (c.-à-d. $\leq 7$ unités de base selon le Tableau des prestations de l'Assurance-santé ontarienne de 2015) réalisées dans les hôpitaux pédiatriques spécialisés vs dans les autres hôpitaux réalisant des chirurgies pédiatriques. Nous avons utilisé l'indice mis au point par Yue et Clayton et le nombre véritable d'interventions courantes (1/indice de Herfindahl) pour quantifier les similitudes et la diversité des interventions chirurgicales pédiatriques réalisées dans ces types d'hôpitaux.

Résultats $A u$ total, 830830 interventions chirurgicales pédiatriques ont été réalisées dans 158 hôpitaux ontariens au cours de la période à l'étude de huit ans. La plupart des interventions chirurgicales réalisées dans les hôpitaux pratiquant des chirurgies pédiatriques n'étaient pas complexes d'un point de vue physiologique (vs $50 \%, P$ $<$ 0,001). L'incidence des interventions non complexes d'un point de vue physiologique a augmenté chaque année dans les hopitaux pédiatriques spécialisés, et cette augmentation a été associée à un déclin réciproque dans les autres hôpitaux. En comparant les hôpitaux spécialisés en pédiatrie aux autres hôpitaux, l'indice moyen de similitude des interventions non complexes d'un point de vue physiologique était moins que modéré $(0,52$; intervalle de confiance [IC] $95 \%, 0,51$ à 0,54). Le véritable nombre moyen d'interventions courantes non complexes d'un point de vue chirurgical (soit la diversité) dans les hôpitaux spécialisés en pédiatrie était plus élevé que dans les 154 autres hôpitaux réalisant des chirurgies pédiatriques $(65,3$ vs 21,8 interventions, respectivement; différence moyenne, 43,5; IC $95 \%, 42,2$ à 44,8; $P<0,001$ ).
Conclusion Les interventions non complexes d'un point de vue physiologique ont progressivement migré vers les hôpitaux pédiatriques spécialisés en Ontario. Les hôpitaux pédiatriques spécialisés se distinguent des autres hôpitaux réalisant des chirurgies pédiatriques principalement par la diversité des interventions, et non par la complexité physiologique de ces dernières. Ces résultats suggèrent que certains types d'interventions chirurgicales pourraient être redistribués des hôpitaux pédiatriques spécialisés vers les autres hôpitaux réalisant des chirurgies pédiatriques.

Enregistrement de l'étude $w w w . c l i n i c a l t r i a l s . g o v$, numéro NCT03144544. Enregistrée le 2 mai 2016.

When considered from a Canadian provincial perspective, determining the type and quantity of surgical procedures undertaken by various hospitals and healthcare networks is necessary for informing resource allocation and modelling healthcare services. Several pediatric advisory panels offer recommendations on the types of surgical procedure that should be undertaken only in specialist pediatric settings. ${ }^{1,2}$ Accordingly, non-physiologically complex procedures (e.g., urethroplasty, myringoplasty) are performed at most hospitals that provide pediatric surgical services, but physiologically complex procedures (e.g., posterior spinal fusion) would be expected to be performed only at pediatric specialist hospitals. Discrimination between the physiological complexity of procedures performed has been used successfully to classify hospitals as specialist or non-specialist, ${ }^{3}$ which has implications for the allocation of provincial resources. In particular, physiologically complex procedures in children often require unique processes, have a disproportionately large effect on operating room efficiency, ${ }^{4-7}$ and are associated with increased rates of perioperative complications. ${ }^{8,9}$

We hypothesized that 1) non-physiologically complex surgical procedures would account for most (> 50\%) pediatric surgical procedures performed at both pediatric specialist hospitals and other hospitals performing pediatric surgery; 2) non-physiologically complex surgical procedures would account for most $(>50 \%)$ inpatient pediatric surgical discharges at both pediatric specialist hospitals and other hospitals performing pediatric surgery; 3 ) the relative distributions of non-physiologically complex surgical procedures, but not physiologically complex procedures, would be at least moderately (index $>0.6$ ) similar between pediatric specialist hospitals and the other hospitals performing pediatric surgery; and 4) the diversity of non-physiologically complex procedures would be greater among pediatric specialist hospitals. To test these four hypotheses, our specific objectives were to estimate 1) 
the incidence of non-physiologically complex pediatric surgical procedures (primary outcome), and 2) the similarity and diversity of non-physiologically and physiologically complex surgical procedures (secondary outcomes) between the pediatric specialist hospitals and other hospitals performing pediatric surgery in Ontario, Canada.

\section{Methods}

With approval (REB1000053805; May 2016) from the local Research Ethics Board, all pediatric surgical procedures performed in Ontario hospitals between April 1, 2007 and March 31, 2015 were identified. This retrospective observational study cohort was constructed from population-based healthcare administrative databases housed at the Institute for Clinical Evaluative Sciences (ICES) ${ }^{10}$ specifically the Discharge Abstract Database and the Same Day Surgery database of the Canadian Institute for Health Information and the Registered Persons Database. Individual-level linkage across databases was performed by ICES. These databases are housed at ICES, were not directly accessible to the study investigators, and consist of demographic, administrative, and clinical data for all hospital discharges (inpatient acute, chronic, rehabilitation) and day surgeries undertaken in Ontario hospitals. These databases undergo rigorous data quality and assurance processes to ensure accuracy of the data submitted to Canadian Institute for Health Information. ${ }^{11}$ This observational study is reported using the Reporting of Studies Conducted Using Observational Routinely Collected Data (RECORD) guideline. ${ }^{12}$

\section{Study population}

Eligible surgical procedures from all intervention code fields of the Discharge Abstract database or Same Day Surgery database within the study time window were documented. Eligible surgical procedures were identified using Canadian Classification of Health Interventions (CCI) therapeutic intervention codes. ${ }^{13}$ All surgical procedures (index event) for individuals aged $>27$ days and $<18 \mathrm{yr}$ on the day of hospital discharge or same day surgery were eligible for inclusion. Procedures excluded were those performed on newborns (aged 0-27 days), records lacking a patient identifier or age, and non-surgical healthcare interventions (e.g., radiation therapy). Newborn interventions were excluded as many are undertaken outside of pediatric hospitals (i.e., in free-standing maternity hospitals), and some commonly performed procedures are undertaken without using operating room or anesthesia resources (e.g., newborn circumcision, tongue-tie release).

\section{Covariates}

Surgical procedures were characterized by the fiscal year of the index event, admission category (ambulatory, elective, newborn, urgent), and pediatric specialty hospital status (i.e., pediatric specialist acute care hospitals $[n=4]$ or other hospitals performing pediatric surgery $[n=154]$ ). Pediatric specialist hospitals were defined as free-standing hospitals providing tertiary pediatric referral services (i.e., Children's Hospital of Eastern Ontario, Children's Hospital of Western Ontario, McMaster Children's Hospital, The Hospital for Sick Children [SickKids], Toronto). Patients were characterized by age category (infant [28-364 days], toddler [1 to $<2 \mathrm{yr}$ ], early childhood [2-5 yr], middle childhood [6-11 yr], and late childhood [12 to $<18 \mathrm{yr}]$ ), home location (urban $v s$ rural), and sex.

As relative value guides for billing have previously been validated as a criterion for discriminating the physiological complexity of surgical procedures, including in Ontario, ${ }^{14,15}$ the physiological complexity of surgical procedures in this cohort was classified using anesthesia basic unit values assigned to individual therapeutic intervention codes in the 2015 Ontario Health Insurance Plan [OHIP] Schedule of Benefits. ${ }^{16}$ Billing units for surgical procedures range from 6 to 40 anesthesia basic units (e.g., 6 units: release of tongue tie; 7 units: removal of renal calculi; 8 units: partial gastrectomy; 9 units: segmental laryngectomy) in the OHIP schedule. Similar to the approach previously used to discriminate physiologically complexity of procedures in Ontario using the American Society of Anesthesiologists relative value guide base units, ${ }^{15}$ in this cohort surgical procedures with $\leq 7$ basic units were classified as nonphysiologically complex (e.g., myringotomy [6 units], reduction of fractures of the elbow or forearm [6-7 units], strabismus repair [6 units]), and surgical procedures with $\geq$ 8 basic units were classified as physiologically complex

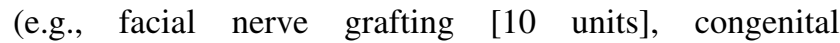
diaphragmatic hernia repair [13 units], craniotomy with excision [15 units]). ${ }^{7,14,15}$

\section{Outcome measures}

Similarity measures estimate the overlap of procedures between hospitals or healthcare networks. ${ }^{6}$ In contrast, measures of diversity provide estimates of the number of distinct procedures performed by individual units. ${ }^{6}$ The methods used to calculate measures of similarity and 
diversity in this study have been reviewed elsewhere ${ }^{6}$ and used previously to describe healthcare utilization in other specialist healthcare populations, including pediatric surgery. ${ }^{3,7,17}$

The similarity of various pediatric surgical procedures was assessed using Yue and Clayton's index. ${ }^{18}$ This similarity measure uses the proportion of both shared and non-shared procedures in each population. For example, if a surgical procedure is selected at random from all of the procedures performed in each of the two groups being compared, the numerator gives the probability that both procedures will be the same and the denominator normalizes the index to between 0 and 1 . This is interpreted in a manner similar to a correlation coefficient, such that $0=$ no overlap between groups in the types of procedures performed and $1=$ the relative frequency for each type of surgical procedure is the same between groups. A similarity index $>0.6$ is considered to represent at least moderate agreement. ${ }^{19}$

The number of distinct types of procedure performed, by location or by specialty type, is an imprecise measure of diversity as it does not consider the relative frequency of procedures. Similarly, the variability observed in the sampling of some infrequent surgical procedures makes the number of different surgical procedures alone an unreliable estimate of activity ${ }^{6}$ as most of these sample estimates miss some procedures that occur infrequently. ${ }^{20}$ The proportion of all interventions attributable to each surgical procedure is a preferable metric as it uses data on how often each type of procedure is relatively performed. The Herfindahl index is calculated as the sum of the squares of the proportions of all procedures in a location that are accounted for by each type of procedure. ${ }^{21}$ The inverse of the Herfindahl index, described as the "effective number of common procedures," has better interpretive value and is reported as a measure of internal diversity. ${ }^{6}$

\section{Statistical analysis}

Descriptive statistics were determined according to prespecified study groups. Comparisons of different methods to estimate the similarity and diversity of surgical procedures undertaken in healthcare settings have been described, as have methods to quantify standard errors (SEs). ${ }^{6}$ The SE for the similarity index was calculated asymptotically using equations 19 to 21 of Dexter et $a l .{ }^{6}$ The SE for the effective number (i.e., diversity) of common procedures was likewise calculated using equation 11 of Dexter $e t a l .{ }^{6}$ These equations, used to estimate similarity and diversity, and their SEs are reproduced in Appendix 1 of the current article. The summary measure method was used to interpret longitudinal data accounting for temporal trends in surgical activity. Statistical significance was defined as two-tailed $P<0.05$. All analyses were performed using SAS 9.4 (SAS Institute, Cary, NC, USA) and Microsoft Excel.

\section{Results}

Surgical procedures and discharges

Descriptive characteristics for the 830,830 pediatric surgical procedures performed in Ontario hospitals during the eight-year study period are summarized in Table 1. Descriptive data classified by discharges (i.e., individual hospitalizations rather than procedures) are summarized in Appendix 2, Table S1 (available as Electronic Supplementary Material). The ten most commonly performed procedures for each type of hospital undertaking pediatric surgery, which were all nonphysiologically complex, accounted for $41.9 \%$ $(n=348,475)$ of the surgical procedures performed by hospitals in the cohort (see Appendix 2, Table S2: available as Electronic Supplementary Material). Length of hospital stay for discharges with only non-physiologically complex procedures are summarized in Appendix 2, Table S3 (available as Electronic Supplementary Material).

Incidence (primary outcome) of non-physiologically complex surgical procedures performed in pediatric hospitals

Non-physiologically complex surgical procedures accounted for the majority of surgical procedures among both the four pediatric specialist hospitals and the other hospitals performing pediatric surgery ( $v S 50 \%, P<0.001$ ), ranging from a mean percentage of 77.1 ( $95 \%$ confidence interval [CI], 76.3 to 77.9 ) at the largest specialist pediatric hospital in Ontario to $97.6 \%$ (95\% CI, 97.4 to 97.7) among the other 154 hospitals performing pediatric surgery (Table 2). The proportion and number of nonphysiologically complex surgical procedures performed at the four pediatric specialist hospitals increased progressively each year (Table 2). This increase was associated with a reciprocal decline in the number of non-physiologically complex surgical procedures performed among the other hospitals undertaking pediatric surgery (Tables 1 and 2).

Most (mean, 93.1\%; 95\% CI, 93.0 to 93.3) surgical discharges-for both inpatient discharges and outpatient visits-were accounted for by patients who underwent nonphysiologically complex procedures only. This finding applied both to the pediatric specialist hospitals and the other hospitals performing pediatric surgery (vs 50\%, both $P<0.001$ ) (Table 3A). When outpatient visits were 
Table 1 Characteristics of all surgical procedures performed for children (aged 28 days to $<18 \mathrm{yr}$ ) in Ontario hospitals between April 2007 and March 2015

\begin{tabular}{|c|c|c|c|c|c|}
\hline Characteristic & $\begin{array}{l}\text { All } \\
\text { hospitals } \\
n=158\end{array}$ & $\begin{array}{l}\text { Non-pediatric } \\
\text { specialist hospitals } \\
n=154\end{array}$ & $\begin{array}{l}\text { Pediatric specialist } \\
\text { hospitals only } \\
n=4\end{array}$ & $\begin{array}{l}\text { Pediatric specialist } \\
\text { hospitals excluding } \\
\text { largest } \\
n=3\end{array}$ & $\begin{array}{l}\text { Largest pediatric } \\
\text { specialist hospital } \\
\text { only } \\
n=1\end{array}$ \\
\hline Surgical procedures, $n$ & 830,830 & 534,368 & 296,462 & 157,947 & 138,515 \\
\hline \multicolumn{6}{|l|}{ Admission category, $n(\%)$} \\
\hline Ambulatory & $601,259(72.4)$ & $456,208(85.4)$ & $145,051(48.9)$ & $94,827(60.0)$ & $50,224(36.3)$ \\
\hline Elective & $114,155(13.7)$ & $31,634(5.9)$ & $82,521(27.8)$ & $29,640(18.8)$ & $52,881(38.2)$ \\
\hline Newborn & $5,326(0.6)$ & $3,243(0.6)$ & $2,083(0.7)$ & $2,083(1.3)$ & $0(0)$ \\
\hline Urgent & $110,090(13.3)$ & $43,283(8.1)$ & $66,807(22.5)$ & $31,397(19.9)$ & $35,410(25.6)$ \\
\hline \multicolumn{6}{|l|}{ Age category, $n(\%)$} \\
\hline Infant (28-364 days) & $50,861(6.1)$ & $10,045(1.9)$ & $40,816(13.8)$ & $15,329(9.7)$ & 25,487 (18.4) \\
\hline Toddler $(1-<2$ yr $)$ & $50,689(6.1)$ & $26,112(4.9)$ & $24,577(8.3)$ & $12,105(7.7)$ & $12,472(9.0)$ \\
\hline Early childhood (2-5 yr) & $297,353(35.8)$ & $207,463(38.8)$ & $89,890(30.3)$ & $53,283(33.7)$ & $36,607(26.4)$ \\
\hline Middle childhood (6-11 yr) & $218,847(26.3)$ & $147,216(27.6)$ & $71,631(24.2)$ & $38,625(24.5)$ & $33,006(23.8)$ \\
\hline Late childhood $(12-<18$ yr $)$ & $213,080(25.7)$ & $143,532(26.9)$ & $69,548(23.5)$ & $38,605(24.4)$ & $30,943(22.3)$ \\
\hline Female sex, $n(\%)$ & 345,647 (41.6) & $223,079(41.8)$ & $122,568(41.3)$ & $64,754(41.0)$ & $57,814(41.7)$ \\
\hline \multicolumn{6}{|l|}{ Residence, $n(\%)$} \\
\hline Missing & $2,177(0.3)$ & $872(0.2)$ & $1,305(0.4)$ & $520(0.3)$ & $785(0.6)$ \\
\hline Urban & $703,504(84.7)$ & $442,513(82.8)$ & $260,991(88.0)$ & $132,420(83.8)$ & $128,571(92.8)$ \\
\hline Rural & $125,149(15.1)$ & $90,983(17.0)$ & $34,166(11.5)$ & $25,007(15.8)$ & $9,159(6.6)$ \\
\hline \multicolumn{6}{|l|}{$\begin{array}{l}\text { Index period (fiscal year) } \\
\text { of treatment, }(n \%)\end{array}$} \\
\hline 2007 & $103,626(12.5)$ & $69,398(13.0)$ & $34,228(11.6)$ & $18,136(11.5)$ & $16,092(11.6)$ \\
\hline 2008 & $104,899(12.6)$ & $69,596(13.0)$ & $35,303(11.9)$ & $18,511(11.7)$ & $16,792(12.1)$ \\
\hline 2009 & $103,322(12.4)$ & $67,569(12.6)$ & $35,753(12.1)$ & 19,192 (12.2) & $16,561(12.0)$ \\
\hline 2010 & $102,314(12.3)$ & $66,525(12.5)$ & $35,789(12.1)$ & $18,948(12.0)$ & $16,841(12.2)$ \\
\hline 2011 & $107,726(13.0)$ & $69,756(13.1)$ & $37,970(12.8)$ & $20,560(13.0)$ & $17,410(12.6)$ \\
\hline 2012 & $103,580(12.5)$ & $65,580(12.3)$ & $38,000(12.8)$ & $20,254(12.8)$ & $17,746(12.8)$ \\
\hline 2013 & $102,057(12.3)$ & 62,899 (11.8) & $39,158(13.2)$ & 21,267 (13.5) & 17,891 (12.9) \\
\hline 2014 & $103,306(12.4)$ & $63,045(11.8)$ & $40,261(13.6)$ & $21,079(13.4)$ & $19,182(13.9)$ \\
\hline \multicolumn{6}{|c|}{ 6-Month period of fiscal year, $n(\%)$} \\
\hline April to September & $425,541(51.2)$ & $276,083(51.7)$ & $149,458(50.4)$ & $79,239(50.2)$ & $70,219(50.7)$ \\
\hline October to March & $405,289(48.8)$ & $258,285(48.3)$ & $147,004(49.6)$ & $78,708(49.8)$ & $68,296(49.3)$ \\
\hline $\begin{array}{l}\text { Admissions to a teaching } \\
\text { hospital, }(n(\%)\end{array}$ & 356,456 (42.9) & $59,994(11.2)$ & $296,462(100)$ & $157,947(100)$ & $138,515(100)$ \\
\hline
\end{tabular}

excluded from this analysis, most (mean, 78.6; 95\% CI, 77.7 to 79.4) discharges were accounted for by patients who underwent non-physiologically complex surgical procedures only (for each hospital type, $P<0.001$ ) (Table 3B).

Similarity of pediatric surgical procedures between types of hospitals performing pediatric surgery

Comparing the non-physiologically complex procedures performed at the four pediatric specialist hospitals and other hospitals performing pediatric surgery, the mean similarity index was less than moderate $(0.52 ; 95 \% \mathrm{CI}$, 0.51 to 0.54 ) (Table 4, column B). Similarity analyses are consistently sensitive to the one or two most common procedures. ${ }^{6,19}$ With such exclusions (i.e., myringotomy, tonsillectomy, adenoidectomy), the mean similarity index between the four pediatric specialist hospitals and the other hospitals performing pediatric surgery increased to moderate $(0.60 ; 95 \%$ CI, 0.59 to 0.61 ) (Table 4, column C). In contrast, the mean similarity index for physiologically complex pediatric surgical procedures performed between these hospitals was, as expected, very low $(0.09 ; 95 \%$ CI, 0.07 to 0.10$)$ (Table 4). There was 
Table 2 Percentage of non-physiologically complex procedures, by year and type of hospital

\begin{tabular}{|c|c|c|c|c|c|c|c|c|c|c|}
\hline \multirow[t]{2}{*}{ Fiscal year } & \multicolumn{2}{|c|}{ All hospitals } & \multicolumn{2}{|c|}{$\begin{array}{l}\text { Non-pediatric specialist } \\
\text { hospitals }\end{array}$} & \multicolumn{2}{|c|}{$\begin{array}{l}\text { Pediatric specialist } \\
\text { hospitals only }\end{array}$} & \multicolumn{2}{|c|}{$\begin{array}{l}\text { Pediatric specialist } \\
\text { hospitals excluding largest }\end{array}$} & \multicolumn{2}{|c|}{$\begin{array}{l}\text { Largest pediatric } \\
\text { specialist hospital only }\end{array}$} \\
\hline & $\%$ & Frequency & $\%$ & Frequency & $\%$ & Frequency & $\%$ & Frequency & $\%$ & Frequency \\
\hline 2007 & 92.7 & $96,088 / 103,626$ & 97.4 & $67,618 / 69,398$ & 83.2 & $28,470 / 34,228$ & 89.5 & $16,225 / 18,136$ & 76.1 & $12,245 / 16,092$ \\
\hline 2008 & 92.5 & $97,034 / 104,899$ & 97.4 & $67,773 / 69,596$ & 82.9 & $29,261 / 35,303$ & 89.4 & $16,558 / 18,511$ & 75.6 & $12,703 / 16,792$ \\
\hline 2009 & 92.5 & $95,565 / 103,322$ & 97.4 & $65,801 / 67,569$ & 83.2 & $29,764 / 35,753$ & 89.6 & $17,201 / 19,192$ & 75.9 & $12,563 / 16,561$ \\
\hline 2010 & 92.8 & $94,981 / 102,314$ & 97.4 & $64,814 / 66,525$ & 84.3 & $30,167 / 35,789$ & 90.8 & $17,206 / 18,948$ & 77.0 & $12,961 / 16,841$ \\
\hline 2011 & 93.3 & $100,455 / 107,726$ & 97.7 & $68,129 / 69,756$ & 85.1 & $32,326 / 37,970$ & 91.3 & $18,761 / 20,560$ & 77.9 & $13,565 / 17,410$ \\
\hline 2012 & 92.9 & $96,257 / 103,580$ & 97.5 & $63,921 / 65,580$ & 85.1 & $32,336 / 38,000$ & 91.6 & $18,550 / 20,254$ & 77.7 & $13,786 / 17,746$ \\
\hline 2013 & 93.1 & $95,029 / 102,057$ & 97.7 & $61,450 / 62,899$ & 85.8 & $33,579 / 39,158$ & 92.1 & $19,593 / 21,267$ & 78.2 & $13,986 / 17,891$ \\
\hline 2014 & 93.0 & $96,109 / 103,306$ & 97.9 & $61,694 / 63,045$ & 85.5 & $34,415 / 40,261$ & 91.8 & $19,344 / 21,079$ & 78.6 & $15,071 / 19,182$ \\
\hline \multicolumn{11}{|l|}{ Summary \%: } \\
\hline mean (SD) & \multicolumn{2}{|c|}{$92.9(0.3)$} & \multicolumn{2}{|c|}{$97.6(0.2)$} & \multicolumn{2}{|c|}{$84.4(1.2)$} & \multicolumn{2}{|c|}{$90.8(1.1)$} & \multicolumn{2}{|c|}{77.1 (1.1) } \\
\hline$(95 \%$ CI) & \multicolumn{2}{|c|}{ (92.7 to 93.0$)$} & \multicolumn{2}{|c|}{ (97.4 to 97.7 ) } & \multicolumn{2}{|c|}{ (83.6 to 85.2$)$} & \multicolumn{2}{|c|}{ (90.0 to 91.5 ) } & \multicolumn{2}{|c|}{ (76.3 to 77.9 ) } \\
\hline vs $50 \%, P$ & \multicolumn{2}{|c|}{$<0.001$} & \multicolumn{2}{|c|}{$<0.001$} & \multicolumn{2}{|c|}{$<0.001$} & \multicolumn{2}{|c|}{$<0.001$} & \multicolumn{2}{|c|}{$<0.001$} \\
\hline
\end{tabular}

$\mathrm{CI}=$ confidence interval

significantly greater similarity for non-physiologically complex procedures than for physiologically complex ones (mean difference, $0.44 ; 95 \% \mathrm{CI}, 0.42$ to $0.45 ; P<$ $0.001)$.

Diversity: effective number of common procedures for types of hospitals performing pediatric surgery

The mean effective number of common nonphysiologically complex procedures (i.e., diversity) was greater among the four pediatric specialist hospitals than the other 154 hospitals performing pediatric surgery for all years studied (65.3 vs 21.8 procedures, respectively; mean difference, $43.5 ; 95 \% \mathrm{CI}, 42.2$ to 44.8 ) (Table 5A). The effective number of common physiologically complex procedures was greater at the four pediatric specialist hospitals than at the other hospitals (Table 5B). However, the mean $[95 \% \mathrm{CI}]$ effective number of common physiologically complex procedures performed at the non-pediatric specialist hospitals was higher than anticipated (35.34 [30.59 to 40.08]). This was partly attributable to multiple CCI subset codes being used to describe similar surgical procedures (e.g., 1.ES.80.LA-XXA [repair of nasal cartilage using an autograft] $v s$ 1.ES.80.LA-XX-E [repair of nasal cartilage using a local flap]). There was also an ordered trend observed for a decreasing effective number of common physiologically complex procedures over time in non-specialist pediatric hospitals. ${ }^{19}$ On sensitivity analysis, this ordered trend was accounted for by a single procedure: partial excision of nasal cartilage with simple apposition.
Comparison of the largest and the other three pediatric specialist hospitals only

When the largest and other three pediatric specialist hospitals were compared in a planned subgroup analysis, the mean $[95 \% \mathrm{CI}]$ similarity index for physiologically complex procedures performed between these groups was less than moderate (0.41 [0.39 to 0.43]). The mean [95\% $\mathrm{CI}$ similarity index was at least moderate for the nonphysiologically complex procedures (0.61 [0.58 to 0.64$])$ reliably so with exclusion of three of the most common procedures (myringotomy, adenoidectomy, tonsillectomy) (0.69 [0.66 to 0.71]) (see Appendix 2, Table S4: available as Electronic Supplementary Material). The effective numbers (i.e., diversity) of common non-physiologically and physiologically complex procedures at the pediatric specialist hospitals are summarized in Tables $5 \mathrm{~A}$ and $5 \mathrm{~B}$, respectively.

\section{Discussion}

From this Ontario population-based study of 830,830 pediatric surgical procedures, we found that the vast majority of the pediatric surgical procedures performed in all types of hospitals (including pediatric specialist hospitals) were non-physiologically complex. This finding was consistent for both inpatient discharges and outpatient visits. Pediatric specialist hospitals had more internal diversity and undertook more types of nonphysiologically complex procedures than the other 
Table 3A Percentage of surgical discharges among patients who underwent non-physiologically complex procedures, by year and pediatric hospital status

\begin{tabular}{|c|c|c|c|c|c|c|c|c|c|c|}
\hline \multirow[t]{2}{*}{ Fiscal year } & \multicolumn{2}{|c|}{ All hospitals } & \multicolumn{2}{|c|}{$\begin{array}{l}\text { Non-pediatric specialist } \\
\text { hospitals }\end{array}$} & \multicolumn{2}{|c|}{$\begin{array}{l}\text { Pediatric specialist } \\
\text { hospitals only }\end{array}$} & \multicolumn{2}{|c|}{$\begin{array}{l}\text { Pediatric specialist hospitals } \\
\text { excluding largest }\end{array}$} & \multicolumn{2}{|c|}{$\begin{array}{l}\text { Largest pediatric } \\
\text { specialist hospital only }\end{array}$} \\
\hline & $\%$ & Frequency & $\%$ & Frequency & $\%$ & Frequency & $\%$ & Frequency & $\%$ & Frequency \\
\hline 2007 & 93.2 & $69,604 / 74,708$ & 97.1 & $51,114 / 52,640$ & 83.8 & $18,490 / 22,068$ & 89.4 & $11,288 / 12,627$ & 76.3 & $7,202 / 9,441$ \\
\hline 2008 & 92.9 & $69,449 / 74,731$ & 97.0 & $50,653 / 52,231$ & 83.5 & $18,796 / 22,500$ & 88.9 & $11,263 / 12,669$ & 76.6 & $7,533 / 9,831$ \\
\hline 2009 & 92.9 & $67,672 / 72,812$ & 97.0 & $48,728 / 50,252$ & 84.0 & $18,944 / 22,560$ & 89.2 & $11,502 / 12,901$ & 77.1 & $7,442 / 9,659$ \\
\hline 2010 & 93.1 & $66,220 / 71,146$ & 97.0 & $47,523 / 48,985$ & 84.4 & $18,697 / 22,161$ & 89.7 & $11,231 / 12,523$ & 77.5 & $7,466 / 9,638$ \\
\hline 2011 & 93.3 & $69,486 / 74,478$ & 97.2 & $49,668 / 51,076$ & 84.7 & $19,818 / 23,402$ & 90.0 & $12,019 / 13,358$ & 77.7 & $7,799 / 10,044$ \\
\hline 2012 & 93.1 & $66,451 / 71,412$ & 97.1 & $46,452 / 47,863$ & 84.9 & $19,999 / 23,549$ & 90.3 & $11,872 / 13,142$ & 78.1 & $8,127 / 10,407$ \\
\hline 2013 & 93.3 & $64,804 / 69,431$ & 97.3 & $44,138 / 45,361$ & 85.9 & $20,666 / 24,070$ & 91.1 & $12,638 / 13,870$ & 78.7 & $8,028 / 10,200$ \\
\hline 2014 & 93.3 & $64,618 / 69,262$ & 97.4 & $43,683 / 44,833$ & 85.7 & $20,935 / 24,429$ & 91.1 & $12,549 / 13,783$ & 78.8 & $8,386 / 10,636$ \\
\hline \multicolumn{11}{|l|}{ Summary \%: } \\
\hline mean (SD) & \multicolumn{2}{|c|}{$93.1(0.2)$} & \multicolumn{2}{|c|}{$97.1(0.2)$} & \multicolumn{2}{|c|}{$84.6(0.9)$} & \multicolumn{2}{|c|}{$90.0(0.8)$} & \multicolumn{2}{|c|}{$77.6(0.9)$} \\
\hline$(95 \% \mathrm{CI})$ & \multicolumn{2}{|c|}{ (93.0 to 93.3 ) } & \multicolumn{2}{|c|}{ (97.2 to 97.0$)$} & \multicolumn{2}{|c|}{ (84.0 to 85.2 ) } & \multicolumn{2}{|c|}{ (89.4 to 90.5 ) } & \multicolumn{2}{|c|}{ (77.0 to 78.2 ) } \\
\hline vs $50 \%, P$ & \multicolumn{2}{|c|}{$<0.001$} & \multicolumn{2}{|c|}{$<0.001$} & \multicolumn{2}{|c|}{$<0.001$} & \multicolumn{2}{|c|}{$<0.001$} & \multicolumn{2}{|c|}{$<0.001$} \\
\hline
\end{tabular}

$\mathrm{CI}=$ confidence interval

Table 3B Percentage of surgical discharges with in-hospital bed nights among patients who underwent non-physiologically complex procedures, by year and pediatric hospital status

\begin{tabular}{|c|c|c|c|c|c|c|c|c|c|c|}
\hline \multirow[t]{2}{*}{ Fiscal year } & \multicolumn{2}{|c|}{ All hospitals } & \multicolumn{2}{|c|}{$\begin{array}{l}\text { Non-pediatric } \\
\text { specialist hospitals }\end{array}$} & \multicolumn{2}{|c|}{$\begin{array}{l}\text { Pediatric specialist } \\
\text { hospitals only }\end{array}$} & \multicolumn{2}{|c|}{$\begin{array}{l}\text { Pediatric specialist hospitals } \\
\text { excluding largest }\end{array}$} & \multicolumn{2}{|c|}{$\begin{array}{l}\text { Largest pediatric } \\
\text { specialist hospital only }\end{array}$} \\
\hline & $\%$ & Frequency & $\%$ & Frequency & $\%$ & Frequency & $\%$ & Frequency & $\%$ & Frequency \\
\hline 2007 & 77.3 & $13,201 / 17,079$ & 90.2 & 7,017/7,779 & 66.5 & $6,184 / 9,300$ & 74.4 & $3,178 / 4,274$ & 59.8 & $3,006 / 5,026$ \\
\hline 2008 & 77.1 & $13,356 / 17,322$ & 90.3 & $6,998 / 7,751$ & 66.4 & $6,358 / 9,571$ & 73.7 & $3,227 / 4,376$ & 60.3 & $3,131 / 5,195$ \\
\hline 2009 & 77.4 & $13,326 / 17,227$ & 90.9 & $6,775 / 7,450$ & 67.0 & $6,551 / 9,777$ & 75.2 & $3,418 / 4,545$ & 59.9 & $3,133 / 5,232$ \\
\hline 2010 & 78.5 & $13,626 / 17,360$ & 91.7 & $6,861 / 7,482$ & 68.5 & $6,765 / 9,878$ & 76.7 & $3,481 / 4,539$ & 61.5 & $3,284 / 5,339$ \\
\hline 2011 & 78.7 & $14,027 / 17,814$ & 92.5 & $7,040 / 7,612$ & 68.5 & $6,987 / 10,202$ & 76.4 & $3,540 / 4,634$ & 61.9 & $3,447 / 5,568$ \\
\hline 2012 & 79.1 & $13,880 / 17,559$ & 92.4 & $6,897 / 7,467$ & 69.2 & $6,983 / 10,092$ & 77.2 & $3,544 / 4,589$ & 62.5 & $3,439 / 5,503$ \\
\hline 2013 & 80.3 & $13,823 / 17,211$ & 93.3 & $6,599 / 7,070$ & 71.2 & $7,224 / 10,141$ & 79.4 & $3,834 / 4,828$ & 63.8 & $3,390 / 5,313$ \\
\hline 2014 & 80.1 & $13,778 / 17,195$ & 94.0 & $6,603 / 7,026$ & 70.6 & $7,175 / 10,169$ & 78.7 & $3,712 / 4,719$ & 63.5 & $3,463 / 5,450$ \\
\hline \multicolumn{11}{|l|}{ Summary \%: } \\
\hline mean (SD) & \multicolumn{2}{|c|}{$78.6(1.2)$} & \multicolumn{2}{|c|}{91.9 (1.4) } & \multicolumn{2}{|c|}{$68.5(1.8)$} & \multicolumn{2}{|c|}{$76.5(2.0)$} & \multicolumn{2}{|c|}{$61.7(1.6)$} \\
\hline$(95 \% \mathrm{CI})$ & \multicolumn{2}{|c|}{ (77.7 to 79.4 ) } & \multicolumn{2}{|c|}{ (91.0 to 92.9 ) } & \multicolumn{2}{|c|}{ (67.2 to 69.7 ) } & \multicolumn{2}{|c|}{ (75.1 to 77.8 ) } & \multicolumn{2}{|c|}{ (60.6 to 62.7 ) } \\
\hline vs $50 \%, P$ & \multicolumn{2}{|c|}{$<0.001$} & \multicolumn{2}{|c|}{$<0.001$} & \multicolumn{2}{|c|}{$<0.001$} & \multicolumn{2}{|c|}{$<0.001$} & \multicolumn{2}{|c|}{$<0.001$} \\
\hline
\end{tabular}

$\mathrm{CI}=$ confidence interval

hospitals performing pediatric surgery. However, the similarity of the non-physiologically complex procedures performed between these hospital types (the four pediatric specialist hospitals and the other 154 hospitals performing pediatric surgery) was found to be at most moderate.

Understanding the types and frequencies of surgical procedures undertaken in hospitals has direct consequences on the allocation of resources among hospitals. Many factors can influence where surgical procedures are undertaken, including distance, hospital attributes, surgeon reputation, wait times, and the preferences of the referring physician. ${ }^{22,23}$ However, many of these factors are mitigated by the regionalization of specialist pediatric services to increase case-load volumes, coordination of care, and improve clinical outcomes. ${ }^{24}$

Pediatric specialist hospitals perform virtually all of the physiologically complex surgery in most healthcare systems, which is inevitable and by design. ${ }^{3,4}$ The vast majority of surgery performed at pediatric specialist hospitals in Ontario, however, is non-physiologically complex-and increasingly so over the studied years (Tables 2 and 3). Although non-pediatric specialist 
Table 4 Similarity indices (standard error) comparing procedures in the four pediatric specialist hospitals with the other hospitals performing pediatric surgery in Ontario

\begin{tabular}{llll}
\hline Fiscal year & \multicolumn{2}{l}{ Type of surgery } & \\
\cline { 2 - 4 } & & Physiologically complex $(\mathrm{A})$ & \multicolumn{2}{l}{ Non-physiologically complex } \\
\cline { 3 - 4 } & & All (B) & Excluding the two most common procedures* (C) \\
\hline 2007 & $0.12(0.01)$ & $0.56(0.01)$ & $0.60(0.01)$ \\
2008 & $0.11(0.01)$ & $0.52(0.01)$ & $0.61(0.01)$ \\
2009 & $0.09(0.01)$ & $0.56(0.01)$ & $0.62(0.01)$ \\
2010 & $0.08(0.01)$ & $0.52(0.01)$ & $0.59(0.01)$ \\
2011 & $0.09(0.01)$ & $0.52(0.01)$ & $0.61(0.01)$ \\
2012 & $0.08(0.01)$ & $0.50(0.01)$ & $0.58(0.01)$ \\
2013 & $0.06(0.01)$ & $0.51(0.01)$ & $0.61(0.01)$ \\
2014 & $0.07(0.01)$ & $0.50(0.01)$ & $0.58(0.01)$ \\
Summary mean $(95 \% \mathrm{CI})$ & $0.09(0.07$ to 0.10$)$ & $0.52(0.51$ to 0.54$)$ & $0.60(0.59$ to 0.61$)$ \\
\hline
\end{tabular}

$\mathrm{CI}=$ confidence interval

*Myringotomy, tonsillectomy, and adenoidectomy (see Table S2)

Comparisons: A to B: mean difference $(95 \% \mathrm{CI}), 0.44(0.42$ to 0.45$), P<0.001 ;$ A to $\mathrm{C}$ : mean difference $(95 \% \mathrm{CI}), 0.51(0.49$ to 0.53$), P<0.001$

Table 5A Effective number (standard error) of common non-physiologically complex procedures at hospitals performing pediatric surgery in Ontario, classified by year and pediatric specialist hospital status

\begin{tabular}{llllll}
\hline Fiscal year & All hospitals & $\begin{array}{l}\text { Non-pediatric } \\
\text { specialist } \\
\text { hospitals }\end{array}$ & $\begin{array}{l}\text { Pediatric } \\
\text { specialist } \\
\text { hospitals only }\end{array}$ & $\begin{array}{l}\text { Pediatric specialist } \\
\text { hospitals excluding } \\
\text { largest }\end{array}$ & $\begin{array}{l}\text { Largest pediatric } \\
\text { specialist hospital } \\
\text { only }\end{array}$ \\
\hline 2007 & $30.17(0.25)$ & $21.86(0.20)$ & $64.38(0.93)$ & $47.84(0.93)$ & $72.32(1.57)$ \\
2008 & $32.86(0.26)$ & $23.51(0.21)$ & $67.07(0.90)$ & $53.15(0.95)$ & $69.38(1.46)$ \\
2009 & $32.60(0.25)$ & $23.43(0.20)$ & $65.21(0.87)$ & $49.93(0.88)$ & $69.43(1.43)$ \\
2010 & $32.35(0.25)$ & $22.55(0.20)$ & $68.06(0.90)$ & $51.51(0.92)$ & $73.47(1.49)$ \\
2011 & $29.28(0.22)$ & $20.20(0.17)$ & $62.26(0.79)$ & $46.82(0.77)$ & $72.15(1.40)$ \\
2012 & $31.30(0.24)$ & $21.07(0.18)$ & $64.98(0.82)$ & $49.81(0.81)$ & $74.19(1.51)$ \\
2013 & $31.70(0.24)$ & $21.11(0.18)$ & $63.05(0.80)$ & $51.58(0.82)$ & $68.32(1.41)$ \\
2014 & $31.76(0.24)$ & $20.65(0.17)$ & $67.40(0.82)$ & $51.21(0.80)$ & $77.86(1.47)$ \\
Summary & $31.50(30.65$ to 32.36) & $21.80(20.93$ to 22.67$)$ & $65.30(63.86$ to 66.75$)$ & $50.23(48.78$ to 51.68$)$ & $72.14(69.98$ to 74.30$)$ \\
mean $(95 \% \mathrm{CI})$ & & & & & \\
\hline
\end{tabular}

$\mathrm{CI}=$ confidence interval

hospitals still perform the majority of pediatric surgery in Ontario (Table 1), non-physiologically complex procedures have progressively migrated to pediatric specialist hospitals from the other hospitals, and there is a substantial overlap in the types of non-physiologically complex pediatric procedures undertaken between these four hospitals and other Ontario hospitals. The similarity for non-physiologically complex procedures was found to be less than moderate, and moderate on sensitivity analyses, both substantially higher than anticipated. These results differ from the pediatric data published from the United States (state of Iowa) estimated using the same methodology. ${ }^{7}$ Differences between these populations can be partly attributed to variations in the fidelity of procedure coding standards used by each of the administrative databases, but geographic factors must also be considered. Despite covering a geographically large area, a substantial proportion of the population of Ontario is located in relatively metropolitan areas compared with Iowa. $^{25,26}$ Increases in these urban populations may also have contributed to the increase in non-physiologically complex procedures performed at pediatric specialist hospitals in Ontario. Nevertheless, the physiological complexity of pediatric surgical procedures defined using the OHIP anesthesia relative value guide (i.e., with a threshold of $\leq 7$ basic units) was able to successfully discriminate between different types of hospitals performing pediatric surgery in Ontario (Tables 2 and 3). 
Table 5B Effective number (standard error) of common physiologically complex procedures at hospitals performing pediatric surgery in Ontario, classified by year and pediatric specialist hospital status

\begin{tabular}{lcllll}
\hline Fiscal year & All hospitals & $\begin{array}{l}\text { Non-pediatric } \\
\text { specialist hospitals }\end{array}$ & $\begin{array}{l}\text { Pediatric specialist } \\
\text { hospitals only }\end{array}$ & $\begin{array}{l}\text { Pediatric specialist } \\
\text { hospitals excluding } \\
\text { largest }\end{array}$ & $\begin{array}{l}\text { Largest pediatric } \\
\text { specialist hospital only }\end{array}$ \\
\hline 2007 & $103.19(3.17)$ & $45.28(2.45)$ & $81.92(3.22)$ & $77.25(4.40)$ & $65.23(3.41)$ \\
2008 & $107.01(3.28)$ & $42.32(2.31)$ & $85.89(3.38)$ & $83.21(4.30)$ & $66.43(3.47)$ \\
2009 & $101.27(3.37)$ & $41.56(2.13)$ & $79.02(3.33)$ & $78.11(4.19)$ & $60.07(3.39)$ \\
2010 & $102.59(3.25)$ & $34.56(1.90)$ & $83.45(3.44)$ & $89.55(5.25)$ & $63.00(3.36)$ \\
2011 & $96.52(3.04)$ & $32.74(1.97)$ & $79.51(3.21)$ & $83.35(4.78)$ & $60.38(3.13)$ \\
2012 & $90.77(3.02)$ & $30.15(1.95)$ & $73.28(3.08)$ & $84.02(4.97)$ & $53.64(2.83)$ \\
2013 & $96.85(3.34)$ & $28.89(1.94)$ & $78.63(3.32)$ & $86.67(5.32)$ & $59.28(3.14)$ \\
2014 & $103.08(3.33)$ & $27.19(2.13)$ & $88.65(3.46)$ & $89.15(5.36)$ & $68.77(3.38)$ \\
Summary mean & $100.16(96.61$ to 103.71$)$ & $35.34(30.59$ to 40.08$)$ & $81.29(77.98$ to 84.61$)$ & $83.91(80.75$ to 87.08$)$ \\
$\quad(95 \% \mathrm{CI})$ & & & & & $62.10(58.78$ to 65.42) \\
\hline
\end{tabular}

$\mathrm{CI}=$ confidence interval

These results suggest real differences in the distribution of pediatric surgical activity in these regional pediatric healthcare systems.

Our findings suggest that when pediatric specialty hospitals are at capacity, pediatric health services in Ontario can potentially be optimized for cost efficiency and case-load volumes by redistributing some types of nonphysiologically complex procedures from specialist pediatric hospitals to the other hospitals performing pediatric surgery. Individual patient complexity must be considered in this system, as it may influence patient referrals; nevertheless, the feasibility and appropriateness of this measure is supported by the fact that these other hospitals already perform most of the pediatric surgery in the province (Table 1).

The health administrative databases used in this study accurately assemble and describe all pediatric surgical hospital procedures in Ontario. The rigorous data quality assurance processes ensure accuracy and validity of these databases. In addition, the study was further strengthened by using a large provincial sampling frame over several years, which mitigated potential regional or temporal variations in the delivery of pediatric healthcare services.

Study limitations include the exclusion of neonatal surgical procedures performed in pediatric hospitals. We were unable to differentiate between neonatal healthcare interventions performed in the operating room and in colocated maternity units (e.g., newborn circumcision) using these administrative databases. Although most neonatal surgical procedures performed in the operating room are likely to be physiologically complex, including this age category would have confounded both the incidence and types of surgical procedures calculated for these hospitals.
Patient co-morbidities and age can also influence hospital referral decisions, but this was not evident in this cohort as a reason for the yearly increase in non-physiologically complex procedures observed at the specialist pediatric hospitals. Specifically, the length of hospital stay (see Appendix 2, Table S3: available as Electronic Supplementary Material) and the proportions in the age categories (see Appendix 2, Table S5: available as Electronic Supplementary Material) for discharges with only non-physiologically complex procedures remained static over time at these hospitals, suggesting that there was no meaningful change in the acuity or age profile of these additional patients. Finally, although our findings provided detailed information about Ontario, our results may not be generalizable to other regions because of differences in geography, referral patterns, access to private healthcare, and procedure coding standards.

In conclusion, this population-based study found that most pediatric surgical procedures performed among all types of hospitals in Ontario are non-physiologically complex. The incidence, similarity, and diversity of these procedures were used to discriminate between hospitals performing pediatric surgery. Whether weighted by the procedure count or discharges, specialty pediatric hospitals are principally dissimilar from other hospitals performing pediatric surgery based not on physiological complexity, but on their diversity. Furthermore, there has been a progressive migration of non-physiologically complex procedures to pediatric specialist hospitals from other hospitals in Ontario. These findings suggest that some types of non-physiologically complex surgical procedures may be redistributed from specialist pediatric hospitals to the other hospitals performing pediatric surgery in Ontario. 
Acknowledgements This study made use of de-identified data from the ICES Data Repository, which is managed by the Institute for Clinical Evaluative Sciences with support from its funders and partners: Canada's Strategy for Patient-Oriented Research (SPOR), the Ontario SPOR Support Unit, the Canadian Institutes of Health Research, and the Government of Ontario. The opinions, results, and conclusions reported are those of the authors. No endorsement by ICES or any of its funders or partners is intended or should be inferred.

Competing interests The Division of Management Consulting, Department of Anesthesia, University of Iowa performs the analyses in this article for hospitals and health systems. FD receives no funds personally other than his salary and allowable expense reimbursements from the University of Iowa, and he has tenure with no incentive program. He and his family have no financial holdings in any company related to his work, other than indirectly through mutual funds for retirement. Income from the Division's consulting work is used to fund Division research.

Editorial responsibility This submission was handled by Dr. Hilary P. Grocott, Editor-in-Chief, Canadian Journal of Anesthesia.

Author contributions James D. O'Leary, Franklin Dexter, David Faraoni, and Mark W. Crawford conceived and designed the study and critically revised the manuscript for important intellectual content. James D. O'Leary and Franklin Dexter carried out the statistical analysis. James D. O'Leary and Franklin Dexter drafted the manuscript. James D. O'Leary is guarantor. The authors assume full responsibility for interpretation of these data.

Funding Mark W. Crawford is supported by The Curtis Joseph and Harold Groves Chair in Anesthesia and Pain Medicine, The Hospital for Sick Children, Toronto. The sponsors had no role in the design or conduct of the study; collection, management, analysis, or interpretation of the data; preparation, review, or approval of the manuscript; or the decision to submit the manuscript for publication.

\section{Appendix 1: Statistical equations}

Let:

$$
j=j^{\text {th }} \text { facility }
$$

$k=1,2, \ldots, \mathrm{S}$, where $\mathrm{S}$ is the total number of procedures performed

$p_{k}=$ the proportion of individual procedures of the $k^{\text {th }}$ type

1. Equations used to calculate the similarity index and its standard error (SE)

The similarity index (from equation 9 of Dexter et al. $\left.2016^{7}\right)$ :

$\hat{\theta}=\frac{\sum_{k=1}^{S} \hat{p}_{1 k} \hat{p}_{2 k}}{\sum_{k=1}^{S} \hat{p}_{1 k}^{2}+\sum_{k=1}^{S} \hat{p}_{2 k}^{2}-\sum_{k=1}^{S} \hat{p}_{1 k} \hat{p}_{2 k}}$.

The estimate of the SE for the similarity index is obtained from equations 19 to 21 of Dexter et al. $2016 .^{7}$

\section{Let}

$\hat{a}=\sum_{k=1}^{S} \hat{p}_{1 k}^{2}$

$\hat{b}=\sum_{k=1}^{S} \hat{p}_{2 k}^{2}$

and

$\hat{d}=\sum_{k=1}^{S} \hat{p}_{1 k} \hat{p}_{2 k}$

Then, the nonparametric maximum likelihood estimator for $\theta$ is $\hat{\theta}=\hat{d} /(\hat{a}+\hat{b}-\hat{d})$.

The estimate of its standard error is the square root of its asymptotic variance:

$$
\begin{aligned}
\operatorname{Var}(\hat{\theta}) \approx & \frac{\hat{d}^{2}}{(\hat{a}+\hat{b}-\hat{d})^{4}}[\operatorname{Var}(\hat{a})+\operatorname{Var}(\hat{b})] \\
& +\frac{(\hat{a}+\hat{b})^{2}}{(\hat{a}+\hat{b}-\hat{d})^{4}} \operatorname{Var}(\hat{d}) \\
- & \frac{2(\hat{a}+\hat{b}) \hat{d}}{(\hat{a}+\hat{b}-\hat{d})^{4}}[\operatorname{Cov}(\hat{a}, \hat{d})+\operatorname{Cov}(\hat{b}, \hat{d})]
\end{aligned}
$$

where:

$$
\begin{aligned}
& \operatorname{Var}(\hat{a}) \approx \frac{4}{n_{1}}\left[\sum_{k=1}^{S} \hat{p}_{1 k}^{3}-\hat{a}^{2}\right] \\
& \operatorname{Var}(\hat{b}) \approx \frac{4}{n_{2}}\left[\sum_{k=1}^{S} \hat{p}_{2 k}^{3}-\hat{b}^{2}\right] \\
& \operatorname{Var}(\hat{d}) \approx \frac{1}{n_{1}} \sum_{k=1}^{S} \hat{p}_{1 k} \hat{p}_{2 k}^{2}+\frac{1}{n_{2}} \sum_{k=1}^{S} \hat{p}_{1 k}^{2} \hat{p}_{2 k}-\left(\frac{1}{n_{1}}+\frac{1}{n_{2}}\right) \hat{d}^{2} \\
& \operatorname{Cov}(\hat{a}, \hat{d}) \approx \frac{2}{n_{1}}\left[\sum_{k=1}^{S} \hat{p}_{1 k}^{2} \hat{p}_{2 k}-\hat{a} \hat{d}\right]
\end{aligned}
$$

and

$\operatorname{Cov}(\hat{b}, \hat{d}) \approx \frac{2}{n_{2}}\left[\sum_{k=1}^{S} \hat{p}_{1 k} \hat{p}_{2 k}^{2}-\hat{b} \hat{d}\right]$

2. Equations used to calculate the effective number of common procedures and its SE

The Herfindahl index $\left(H_{j}\right)$ is calculated as the sum of the squares of the proportions of all procedures at a hospital that are accounted for by each type of procedure. The Herfindahl index is (from equation 1 of Dexter et al. $\left.2016^{7}\right)$ :

$$
H_{j}=\sum_{k=1}^{S} p_{j k}^{2}
$$


The effective number of common procedures is the inverse of the Herfindahl Index $\left(1 / H_{j}\right)$.

Using the first-order Taylor series expansion (i.e., delta method), the standard error for the maximum likelihood estimate for $\hat{H}_{j}$ equals (from equation 11 of Dexter et al. $\left.2016^{7}\right)$ :

$$
\sqrt{\frac{4}{n_{j}}\left[\sum_{k=1}^{s} \hat{p}_{j k}^{3}-\left(\sum_{k=1}^{s} \hat{p}_{j k}^{2}\right)^{2}\right]}
$$

Dexter et al. 2016 showed that, when using additional terms, the differences in the calculated standard errors are in the fourth or fifth decimal places (i.e., negligible). ${ }^{7}$ Using the first-order Taylor series expansion, the SE of the inverse of the Herfindahl is approximately equal to the above equation divided by $\hat{H}_{j}^{2}$.

\section{References}

1. Surgical Advisory Panel. American Academy of Pediatrics, Klein MD. Referral to pediatric surgical specialists. Pediatrics 2014; 133: $350-6$

2. Task Force for Children's Surgical Care. Optimal resources for children's surgical care in the United States. J Am Coll Surg 2014; 218: 479-87, 487.e1-4.

3. Kanter RK, Dexter F. Criteria for identification of comprehensive pediatric hospitals and referral regions. J Pediatr 2005; 146: 26-9.

4. Dexter F, Wachtel RE, Yue JC. Use of discharge abstract databases to differentiate among pediatric hospitals based on operative procedures: surgery in infants and young children in the state of Iowa. Anesthesiology 2003; 99: 480-7.

5. Dexter F, Dexter EU, Ledolter J. Influence of procedure classification on process variability and parameter uncertainty of surgical case durations. Anesth Analg 2010; 110: 1155-63.

6. Dexter F, Ledolter J, Tiwari V, Epstein RH. Value of a scheduled duration quantified in terms of equivalent numbers of historical cases. Anesth Analg 2013; 117: 205-10.

7. Dexter F, Ledolter J, Hindman BJ. Quantifying the diversity and similarity of surgical procedures among hospitals and anesthesia providers. Anesth Analg 2016; 122: 251-63.

8. Finks JF, Osborne NH, Birkmeyer JD. Trends in hospital volume and operative mortality for high-risk surgery. N Engl J Med 2011; 364: 2128-37.

9. Reames BN, Ghaferi AA, Birkmeyer JD, Dimick JB. Hospital volume and operative mortality in the modern era. Ann Surg 2014; 260: 244-51.

10. Institute for Clinical Evaluative Sciences. Available from URL: http://www.ices.on.ca (accessed September 2017).
11. Canadian Institute for Health Information. Standards and Data Submission. Data Quality Documentation, Discharge Abstract Database-Multi-Year Information; 2012. Available from URL: https://www.cihi.ca/en/dad_multi-year_en.pdf (accessed September 2017).

12. Benchimol EI, Smeeth L, Guttmann A, et al. The REporting of studies Conducted using Observational Routinely-collected health Data (RECORD) statement. PLoS Med 2015; 12: e1001885.

13. Canadian Classification of Health Interventions. Available from URL: https://www.cihi.ca/en/submit-data-and-view-standards/ codes-and-classifications/cci (accessed September 2017).

14. Dexter F, Thompson E. Relative value guide basic units in operating room scheduling to ensure compliance with anesthesia group policies for surgical procedures performed at each anesthetizing location. AANA J 2001; 69: 120-3.

15. Dexter F, Macario A, Penning DH, Chung P. Development of an appropriate list of surgical procedures of a specified maximum anesthetic complexity to be performed at a new ambulatory surgery facility. Anesth Analg 2002; 95: 78-82.

16. Ontario Ministry of Health and Longterm Care. Ontario Health Insurance Plan - OHIP Schedule of Benefits and Fees; 2012. Available from URL: http://www.health.gov.on.ca/en/pro/ programs/ohip/sob/ (accessed September 2017).

17. Wachtel RE, Dexter $F$. Differentiating among hospitals performing physiologically complex operative procedures in the elderly. Anesthesiology 2004; 100: 1552-61.

18. Yue JC, Clayton MK. A similarity measure based on species proportions. Communications in Statistics-Theory and Methods 2005; 34: 2123-31.

19. Wachtel RE, Dexter F, Barry B, Applegeet $C$. Use of state discharge abstract data to identify hospitals performing similar types of operative procedures. Anesth Analg 2010; 110: 1146-54.

20. Dexter F, Traub RD, Fleisher LA, Rock P. What sample sizes are required for pooling surgical case durations among facilities to decrease the incidence of procedures with little historical data? Anesthesiology 2002; 96: 1230-6.

21. Dayhoff DA, Cromwell J. Measuring differences and similarities in hospital caseloads: a conceptual and empirical analysis. Health Serv Res 1993; 28: 293-312.

22. Wilson CT, Woloshin S, Schwartz LM. Choosing where to have major surgery: who makes the decision? Arch Surg 2007; 142: 242-6.

23. Yahanda AT, Lafaro KJ, Spolverato G, Pawlik TM. A systematic review of the factors that patients use to choose their surgeon. World J Surg 2016; 40: 45-55.

24. Lorch SA, Myers S, Carr B. The regionalization of pediatric health care. Pediatrics 2010; 126: 1182-90.

25. Iowa State University. Rural and Urban Population. Available from URL: http://www.icip.iastate.edu/tables/population/ruralurban (accessed Septmber 2017).

26. Statistics Canada. Population, urban and rural, by province and territory (Ontario), 2011. Available from URL: http://www. statcan.gc.ca/tables-tableaux/sum-som/101/cst01/demo62g-eng. htm (accessed September 2017). 